\title{
Reaction Mechanism of Ferrosilicon Synthesis Using Waste Plastic as a Reductant
}

\author{
Rifat FARZANA, ${ }^{*}$ Ravindra RAJARAO and Veena SAHAJWALLA \\ Centre for Sustainable Materials Research and Technology (SMaRT) School of Materials Science and Engineering, UNSW \\ Australia, Sydney, NSW 2052 Australia.
}

(Received on April 21, 2017; accepted on June 19, 2017)

\begin{abstract}
Reaction mechanism study of ferrosilicon synthesis was carried out by using reagent grade material, graphite and waste plastic, Bakelite as reducing agent over a temperature range of $1623 \mathrm{~K}$ to $1823 \mathrm{~K}$ $\left(1350^{\circ} \mathrm{C}\right.$ to $\left.1550^{\circ} \mathrm{C}\right)$ under inert atmosphere. Reaction rate was determined by using off-gases evolving from reduction reactions. Results showed that reduction mechanism was predominantly controlled by chemical reactions with both the reducing agent. Initially Bakelite bearing pellet showed faster reaction rate compared to graphite due to volatiles generation and less crystalline nature of Bakelite derived carbon. Extent of reduction can be improved by increasing temperature; however Bakelite bearing pellet showed lower dependency on temperature compared to graphite. Activation energy for graphite and Bakelite pellet is $238.07 \mathrm{~kJ} / \mathrm{mol}$ and $140.29 \mathrm{~kJ} / \mathrm{mol}$ respectively. This comparative study will create new opportunities to use waste Bakelite as a reductant even at moderately lower temperature to synthesise ferrosilicon alloy.
\end{abstract}

KEY WORDS: ferrosilicon; reaction kinetics; reaction mechanism; waste plastic; bakelite.

\section{Introduction}

The production process of ferrosilicon involves carbothermal reduction of silica and iron oxide with carbon in an electric arc furnace, ${ }^{1)}$ the primary reactant materials include quartz, hematite and coke/coal. The most common ferrosilicon alloy phases are $\mathrm{Fe}_{3} \mathrm{Si}$ (Suessite or Gupeite), $\mathrm{Fe}_{5} \mathrm{Si}_{3}$ (Xifengite), $\mathrm{FeSi}_{2}$ (Ferdisilite), FeSi (Fersilite). Ferrosilicon production uses up to $10.5 \mathrm{MWh}$ of electrical energy per tonne of ferrosilicon due to endothermic nature of reduction process. ${ }^{2)}$ China is major producer of ferrosilicon alloy and this alloy is widely used in as an additive for silicon and as a deoxidising element in cast iron and steel making industries and foundries. The reactivity of the reduction material is important to achieve high silicon yield in the ferrosilicon alloy and attributed to the major cost in production system. ${ }^{3)}$ Typically coal, charcoal, coke, woodchips are widely used reduction materials in silicon industry. Wood chips originate from hardwood not only used as reductant but also to enhance the permeability of the charged material to achieve good gas flow. The complex structure of coal/ coke contains network of pores which gives high surface area and have higher fixed Carbon. The choice of reduction material depends on the process, product and environmental considerations. The material must have properties to reach high Si yield, eliminate the chance of unwanted materials in product or emission like phosphorus, mercury etc. Besides general requirements, silicon monoxide $(\mathrm{SiO})$ reactivity is

\footnotetext{
* Corresponding author: E-mail: r.farzana@unsw.edu.au DOI: http://dx.doi.org/10.2355/isijinternational.ISIJINT-2017-199
}

very important. The $\mathrm{SiO}$ reactivity is the ability of carbon, in the form of coke/coal, to react with $\mathrm{SiO}$, and form $\mathrm{SiC}$ and CO. Studies were conducted to investigate the effect of reduction material properties on ferrosilicon alloy production. ${ }^{4,5)}$ Also, a number of studies have investigated reaction mechanism and kinetics for silica to $\mathrm{SiC}$ or silicon formation using conventional reduction materials. ${ }^{6-10)}$ However, limited studies are found to investigate reaction kinetics for ferrosilicon alloy synthesis. Therefore, a comparative study of reaction kinetics and mechanism of ferrosilicon alloy formation was conducted by measuring the off gases coming from the reduction reactions using graphite and waste Bakelite as reducing agent.

Bakelite is extensively used in electrical and heavy duty automotive parts, kitchenware, washing machine impeller etc. due to its high hardness, strength, electrical and thermal insulating properties. ${ }^{11,12)}$ Since, Bakelite cannot be remoulded; it is difficult to recycle and hence generally landfilled.

From our group, we reported kinetic studies of carbon composite pellets using graphite ${ }^{13)}$ and silica reduction studies using graphite-Bakelite blend. ${ }^{14)}$ Bakelite transformation as reductants for ferrosilicon alloy synthesis is also reported. ${ }^{15)}$

In this paper, a fundamental comparative study on reaction kinetics and mechanism of ferrosilicon alloy synthesis, using reagent grade material, graphite and waste plastic, Bakelite as reducing agent within $1623 \mathrm{~K}$ to $1823 \mathrm{~K}$ $\left(1350^{\circ} \mathrm{C}\right.$ to $\left.1550^{\circ} \mathrm{C}\right)$ is reported. Influence of temperature on ferrosilicon synthesis is also reported. Infrared Gas Analyzer (IR) was used to determine off gas analysis 
coming from reduction reactions to determine the reaction kinetics. Reaction product was characterized by X-ray diffraction (XRD), scanning electron microscopy (SEM) and energy dispersive X-ray spectroscopy (EDS) analysis. It was observed that reaction rate is strongly dependent on the temperature and activation energy for graphite and Bakelite bearing pellet is $238.07 \mathrm{~kJ} / \mathrm{mol}$ and $140.29 \mathrm{~kJ} / \mathrm{mol}$ respectively. Lower activation energy using Bakelite creates the opportunity to use waste Bakelite as reducing agent at lower temperature compared to conventional carbon materials to synthesise ferrosilicon alloy.

\section{Experimental}

Spherical pellets (2 gm, 10-12 $\mathrm{mm}$ in diameter) were made with silica $\left(\mathrm{SiO}_{2}\right)$ powder $(0.5-10 \mu \mathrm{m}, 99 \%)$, iron oxide $\left(\mathrm{Fe}_{2} \mathrm{O}_{3}\right)$ powder $(<5 \mu \mathrm{m}, \geq 99 \%)$ and synthetic graphite (C) powder $(<20 \mu \mathrm{m}) /$ Bakelite $(125 \mu \mathrm{m})$. Generally, as particle size decreases, the rate of reduction reaction increases. Although, size of Bakelite particle (125 $\mu \mathrm{m})$ is higher than graphite $(20 \mu \mathrm{m})$, in this study higher reduction rate was observed for Bakelite. Required amount of carbon was measured from molar ratio of the stoichiometric reactions to produce ferrosilicon (reactions $(1),(2)) .{ }^{16)}$ Therefore, weight ratio of synthetic graphite $(\sim 100 \% \mathrm{C})$ containing pellets was $\mathrm{SiO}_{2}$ : $\mathrm{C}$ (synthetic graphite): $\mathrm{Fe}_{2} \mathrm{O}_{3}$ (1:0.62:1). Bakelite containing pellets were made with weight ratio $\mathrm{SiO}_{2}$ : $\mathrm{C}$ (Bakelite): $\mathrm{Fe}_{2} \mathrm{O}_{3}$ as 1:0.46:1 taking into account that $\% \mathrm{C}$ in Bakelite char is $73.16 \%{ }^{16)}$ Pellet preparation method used in the present study was identical to previous studies. ${ }^{16-18)}$ To remove any moisture content, pellets were dried for 24 hours at $\sim 90^{\circ} \mathrm{C}$. Chemical analysis of Bakelite is shown in Tables 1(a) and 1(b).

A schematic of the experimental set-up is in Fig. 1. A

Table 1. (a). Chemical composition of Bakelite. (b). Composition of Ash analysis of Bakelite.

(a)

\begin{tabular}{|c|c|c|c|}
\hline \multicolumn{4}{|c|}{ Composition (wt\%) } \\
\hline \multicolumn{2}{|c|}{ Ultimate Analysis } & \multicolumn{2}{|c|}{ Proximate Analysis } \\
\hline Total carbon & 53.4 & Fixed Carbon & 31.70 \\
\hline Oxygen & 11.6 & Volatiles & 47.55 \\
\hline Hydrogen & 4.0 & Moisture & 3.01 \\
\hline Sulphur & 0.017 & Ash & 17.74 \\
\hline
\end{tabular}

(b)

\begin{tabular}{cccc}
\hline Compound & $\mathrm{CaO}$ & $\mathrm{SiO}_{2}$ & $\mathrm{SO}_{3}$ \\
\hline $\mathrm{wt} \%$ & 94.53 & 5.14 & 0.33 \\
\hline
\end{tabular}

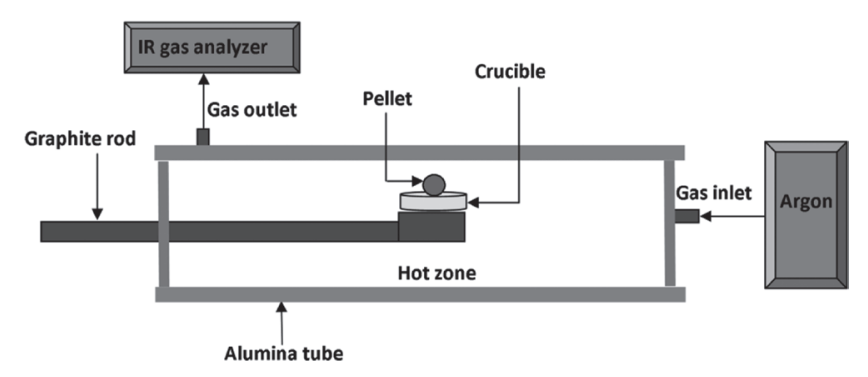

Fig. 1. Schematic diagram of experimental set-up. horizontal tube furnace equipped with super kanthal heating elements was used for heat treatment of pellets from $1623 \mathrm{~K}$ to $1823 \mathrm{~K}\left(1350^{\circ} \mathrm{C}\right.$ to $\left.1550^{\circ} \mathrm{C}\right)$. High purity (> 99\%) argon gas was flowing at $0.8 \mathrm{~L} / \mathrm{min}$ through gas inlet. The tube was sealed with a rubber O-ring and grease in order to avoid contamination from atmosphere and off-gas leakage. Constant gas flow was controlled by a gas flowmeter at gas inlet. Inferred gas analyser, IR (ABB, Advanced Optima Series, AO2020) was connected at gas outlet to measure $\mathrm{CO}, \mathrm{CO}_{2}$ and $\mathrm{CH}_{4}$ off gases coming from reduction reactions. Gas analysis data were taken three times and average was taken into account for calculations to ensure reproducibility. $\mathrm{CO}$ and $\mathrm{CO}_{2}$ gas generation were used to determine reaction kinetics and cumulative volume of gases was measured to estimate reaction rate. Gas concentrations data ppm (parts per million) from IR gas analyzer were converted into moles using standard gas equation. Reaction product was analysed by XRD (PAN analytical Xpert Multipurpose MPD). Copper $\mathrm{K} \alpha$ radiation of $45 \mathrm{kV}$ and $40 \mathrm{~mA}$ was used as an X-ray source, under the step size of $0.026^{\circ}$ with $1^{\circ}$ slit and $10 \mathrm{~mm}$ mask. Phase identification was done by using Xpert High Score Plus software. Synthesiszed ferrosilicon was also confirmed by SEM (Hitachi 3400-I) and EDS (Bruker X flash 5010) analysis.

\section{Results and Discussion}

Analyzing the reaction off-gas is an effective and dynamic method to determine the reaction controlling the reduction process. Therefore reaction kinetics and mechanism was determined by measuring off-gases released from the graphite and Bakelite bearing pellets. Figure 2 is showing the generated gas concentration of graphite and Bakelite pellet. It was observed that $\mathrm{CO}$ gas was the dominant in off-gas release which was produced through the reduction reactions (reactions (1), (2)) for ferrosilicon synthesis.

$$
\begin{aligned}
& \mathrm{SiO}_{2}(\mathrm{~s})+2 \mathrm{C}(\mathrm{s}) \rightarrow \mathrm{Si}(\mathrm{s} / \mathrm{l})+2 \mathrm{CO}(\mathrm{g}) \ldots \ldots \ldots . . . \text { reaction (1) } \\
& \mathrm{Fe}_{2} \mathrm{O}_{3}(\mathrm{~s})+3 \mathrm{C}(\mathrm{s}) \rightarrow 2 \mathrm{Fe}(\mathrm{s}, 1)+3 \mathrm{CO}(\mathrm{g}) \ldots \ldots \ldots \text { reaction (2) }
\end{aligned}
$$

Though CO gas release was comparatively high at initial stage in Bakelite pellet but released over a longer period of time in graphite pellet. Gases coming from the Bakelite degradation $\left(\mathrm{CO}\right.$ and $\mathrm{CH}_{4}$ ) enhanced the reduction reactions (reactions (3), (4)) initially therefore higher CO release was observed.

$$
\begin{gathered}
\mathrm{SiO}_{2}(\mathrm{~s})+\mathrm{CO}(\mathrm{g}) \rightarrow \mathrm{SiO}(\mathrm{g})+\mathrm{CO}_{2}(\mathrm{~g}) \ldots \ldots . . . \text { reaction (3) } \\
\mathrm{SiO}_{2}(\mathrm{~s})+\mathrm{CH}_{4}(\mathrm{~g}) \rightarrow \mathrm{SiO}(\mathrm{g})+\mathrm{CO}(\mathrm{g})+2 \mathrm{H}_{2}(\mathrm{~g})
\end{gathered}
$$

At $1823 \mathrm{~K}\left(1550^{\circ} \mathrm{C}\right)$, Bakelite generates significant amount of gases within 4 minutes and showed $69.47 \%$ carbon content in the solid residue. ${ }^{15)}$ Concurrently, from XRD analysis of Bakelite char, it was observed that crystalline nature of Bakelite derived carbon was becoming more evident after 4 minutes onwards (Fig. 3) and that carbon started to reduce oxides, therefore the highlighted neck (Orange circle in Fig. 2 ) in Bakelite pellet can be attributed to the transition from gas phase to solid phase reduction reactions. Afterwards, as the supply of Bakelite derived 

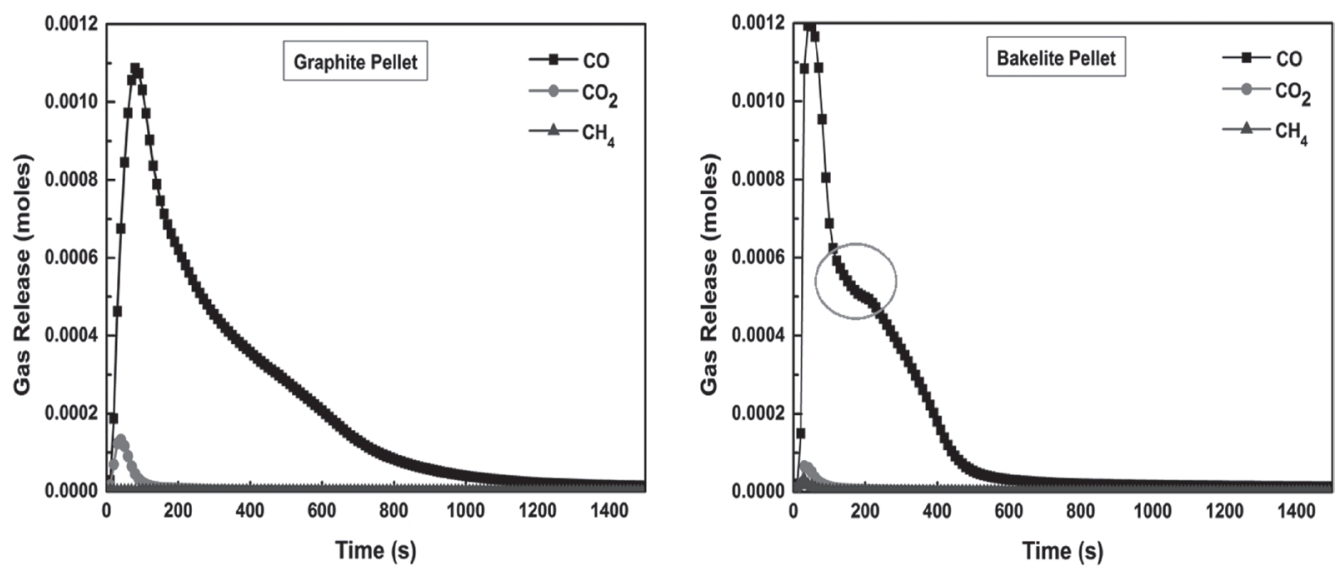

Fig. 2. Generated gas concentration from graphite and Bakelite pellet at temperature $1823 \mathrm{~K}\left(1550^{\circ} \mathrm{C}\right)$ during synthesis of ferrosilicon.

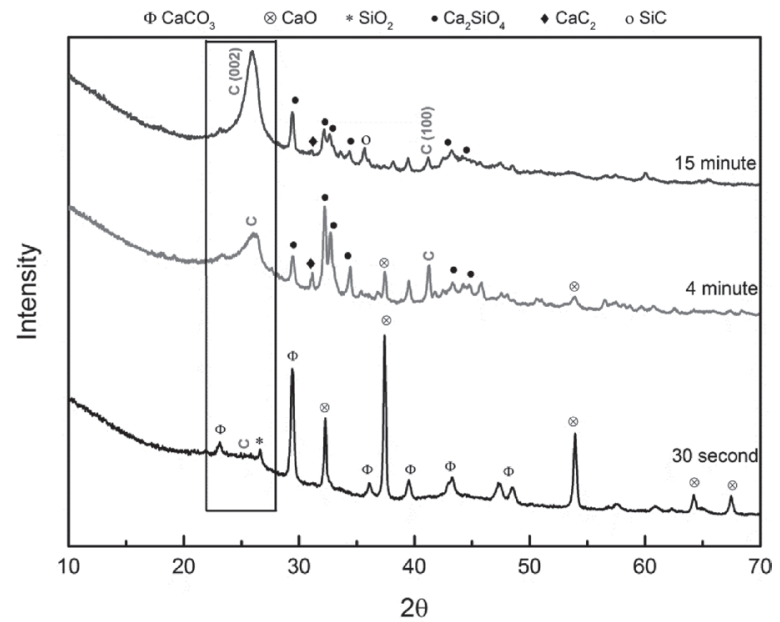

Fig. 3. XRD analysis of Bakelite chars at temperature $1823 \mathrm{~K}$ $\left(1550^{\circ} \mathrm{C}\right)$

carbon was used up and was lower than the graphite, the reactions reached almost completion before graphite pellet. $\mathrm{CO}_{2}$ which is the main source of greenhouse gas was lower in Bakelite pellet compared to graphite pellet. ${ }^{15)}$ Graphite pellet did not show any trace of $\mathrm{CH}_{4}$ gas, whereas Bakelite showed small amount of $\mathrm{CH}_{4}$ due to degradation of Bakelite and a major portion of $\mathrm{CH}_{4}$ gas helped reduction reactions (reaction $(4))^{14,19)}$

Figure 4 compares the total amount of oxygen removal with time temperature of $1623 \mathrm{~K}, 1723 \mathrm{~K}$ and $1823 \mathrm{~K}$ $\left(1350^{\circ} \mathrm{C}, 1450^{\circ} \mathrm{C}, 1550^{\circ} \mathrm{C}\right)$ due to the reactions occurring within the graphite and Bakelite bearing pellet. Total cumulative oxygen was measured from the ppm values of $\mathrm{CO}$ and $\mathrm{CO}_{2}$ evolved during the reduction reactions by graphite and Bakelite. An almost linear increase in the initial stage followed by limiting values of cumulative oxygen removal was observed in all temperatures for both graphite and Bakelite bearing pellets as reactants are exhausted. It can be also observed that reduction reactions to synthesise ferrosilicon using graphite and Bakelite are temperature dependent which is found in previous studies ${ }^{20)}$ as well. Extent of reduction can be improved by increasing temperature. However, Bakelite pellet showed lower dependency on temperature compared to graphite. At $1623 \mathrm{~K}\left(1350^{\circ} \mathrm{C}\right)$ and 1723 $\mathrm{K}\left(1450^{\circ} \mathrm{C}\right)$ Bakelite pellet showed almost same amount of
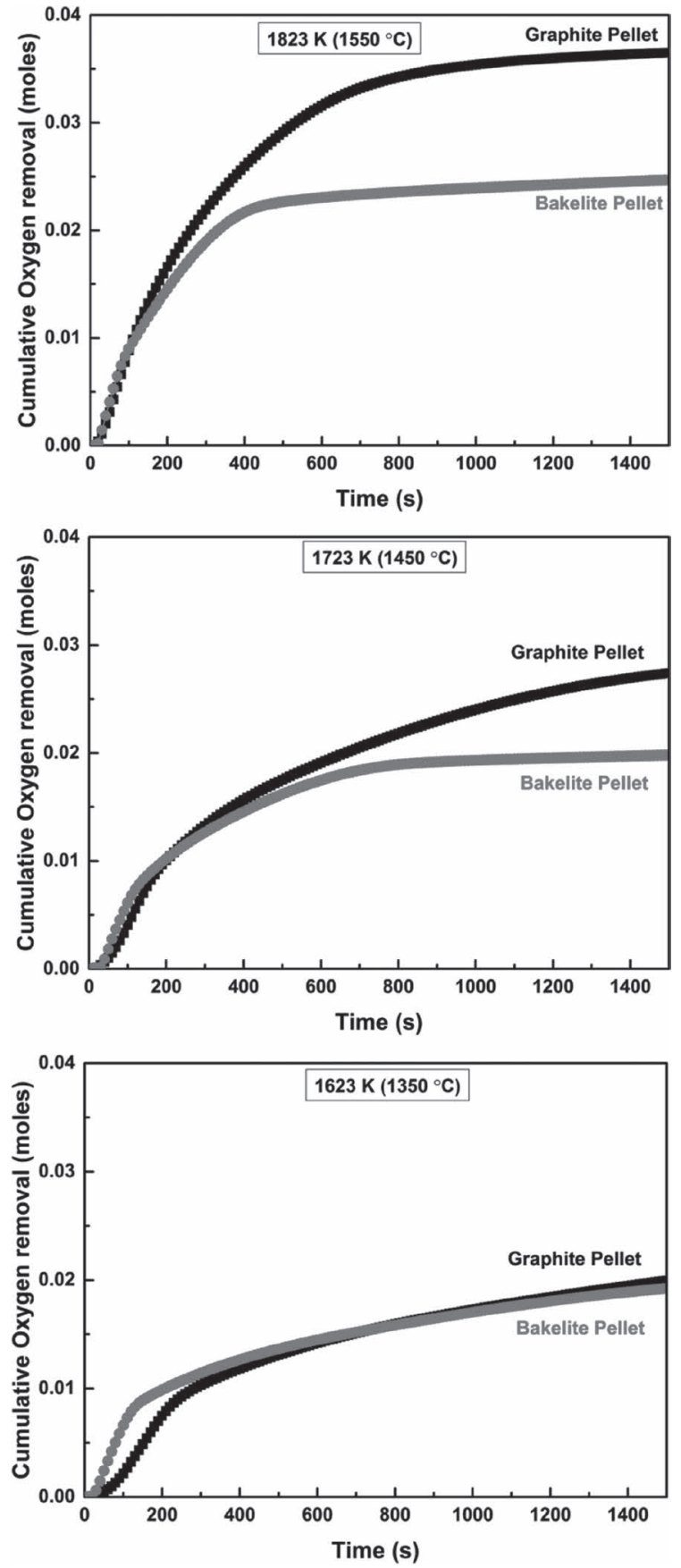

Fig. 4. Cumulative oxygen removal from graphite and Bakelite pellet at different temperature during synthesis of ferrosilicon. 
oxygen removal and at $1823 \mathrm{~K}\left(1550^{\circ} \mathrm{C}\right)$ Bakelite pellet showed gradual increase in oxygen removal. This behavior of Bakelite can be attributed to the reactivity of Bakelite at lower temperature due to initial gas release from Bakelite degradation and less crystalline nature of Bakelite derived carbon compared to graphite. Alternatively graphite pellet showed almost double amount of oxygen removal from $1623 \mathrm{~K}$ to $1823 \mathrm{~K}\left(1350^{\circ} \mathrm{C}\right.$ to $\left.1550^{\circ} \mathrm{C}\right)$ temperature. At $1823 \mathrm{~K}\left(1550^{\circ} \mathrm{C}\right)$ both graphite and Bakelite pellet showed flat limiting values at the end however at $1623 \mathrm{~K}\left(1350^{\circ} \mathrm{C}\right)$ and $1723 \mathrm{~K}\left(1450^{\circ} \mathrm{C}\right)$ within 15 minutes $(1500 \mathrm{sec})$ it showed gradual increase which refers that at lower temperature reduction rate become slower therefore requires more time to reach the equilibrium condition.

The overall reduction is divided into three stages considering the slope of the curve of cumulative oxygen removal or reduction extent over time. Reduction extent was measured using Eq. (1). Figure 5 is showing the reduction extent for graphite and Bakelite pellet at $1823 \mathrm{~K}\left(1550^{\circ} \mathrm{C}\right)$ with graphical representation. Stages in pellet reactions were compared and determined on change in slope of the curve in reduction extent over time plot (Fig. 5) and in $\ln \left(\mathrm{P}_{\mathrm{co}} /\right.$ $\left.\mathrm{P}_{\mathrm{co} 2}\right)$ over time plot, shown in Fig. 8. At stage $1(0-120 \mathrm{sec})$, linear and sharp increase in reduction reaction is observed, due to $\mathrm{Fe}_{2} \mathrm{O}_{3}$ reduction and initial $\mathrm{SiO}_{2}$ reduction ${ }^{15)}$ and graphically showed size reduction. Reduction product was confirmed by the XRD and EDS analysis as shown in Figs. 6 and 7.

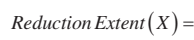

In stage $2(120 \mathrm{sec}-900 \mathrm{sec})$, most of reduction reactions occurred, and is divided into two regions. In stage 2-I, a steady state reaction region was observed which was followed by stage 2-II, where a slowing down of reactions occurred due to the formation of final product (ferrosilicon) and slag $\left(\mathrm{SiC}, \mathrm{CaSiO}_{3} / \mathrm{Ca}_{2} \mathrm{SiO}_{4}\right)$ through reduction (Fig. 6). In-situ image also showed nucleation of metal droplets and slag phase. In stage 3, reactions reached almost completion

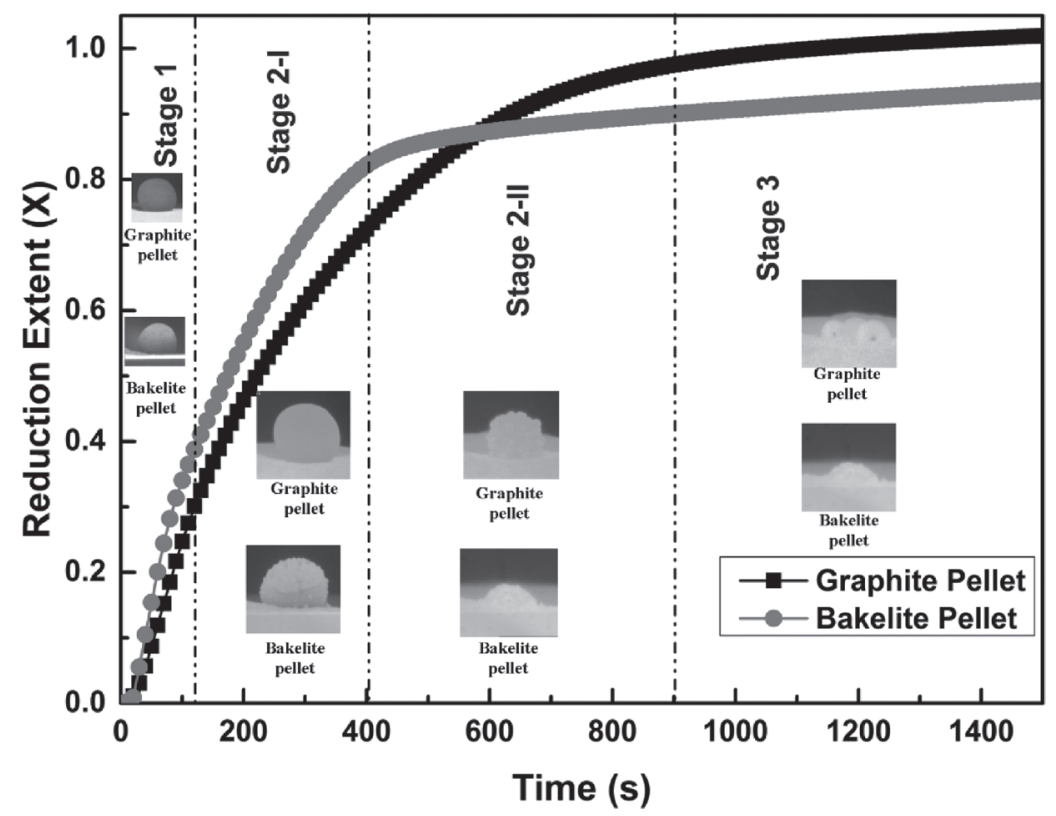

Fig. 5. Reduction extent for the graphite and Bakelite pellet at $1823 \mathrm{~K}\left(1550^{\circ} \mathrm{C}\right)$ during synthesis of ferrosilicon.
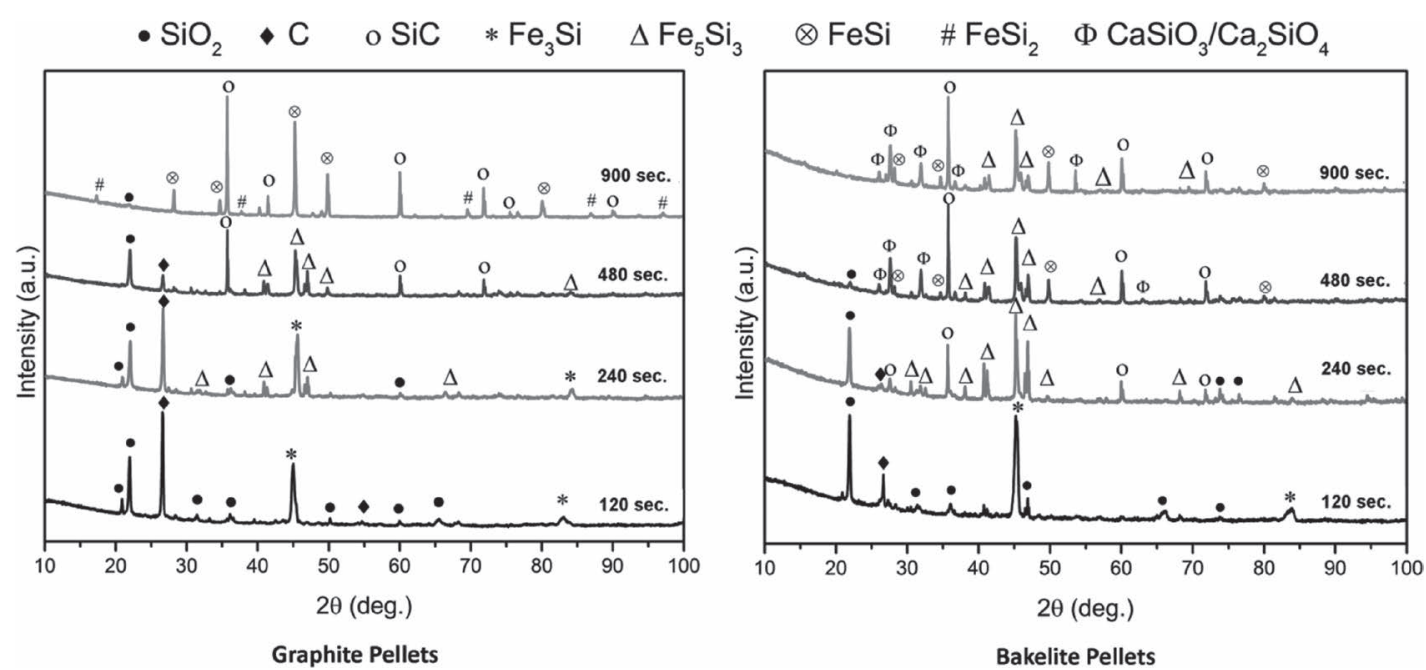

Fig. 6. Comparison of XRD analysis of Graphite and Bakelite pellet at $1823 \mathrm{~K}\left(1550^{\circ} \mathrm{C}\right)$ during synthesis of ferrosilicon. 

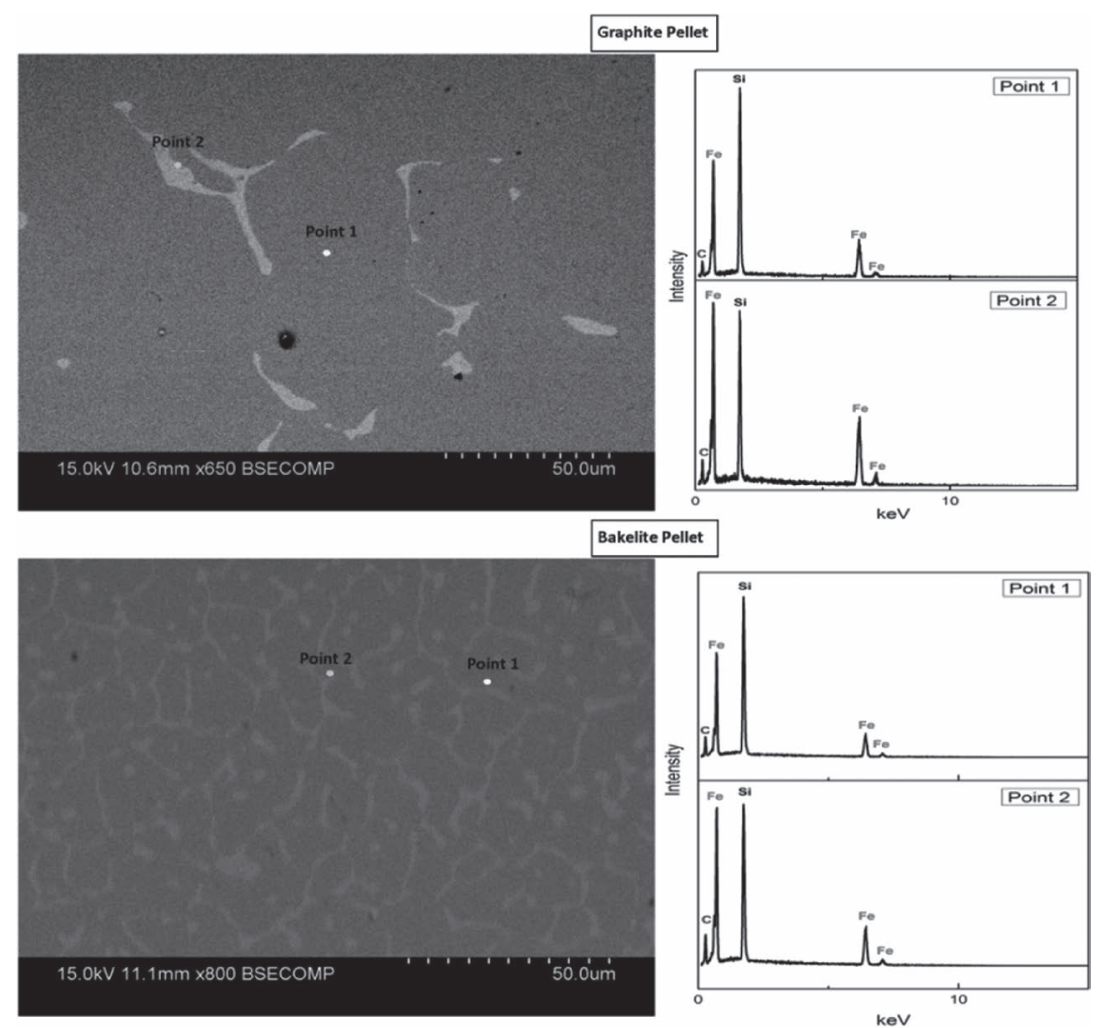

Fig. 7. SEM and EDS analysis of ferrosilicon alloy synthesised by Graphite and Bakelite.

and therefore the reduction extent curve become steady and distinctively it showed metal and slag phases. Overall, graphite pellet showed complete reduction $(100 \%)$ through formation of ferrosilicon as product and $\mathrm{SiC}$ in slag. Alternatively, formation of viscous slag $\mathrm{CaSiO}_{3} / \mathrm{CaSiO}_{4}$ in Bakelite pellet and lower amount of Bakelite derived carbon can be attributed to the comparatively lower reduction extent $(\sim 92 \%)$ and preceding steady state than graphite pellet. However, Bakelite pellet showed enhanced extent of reaction up to $\sim 600 \mathrm{sec}$ (stage 2) which can be observed from the gradient of the curves of graphite and Bakelite in Fig. 5.

Formation of ferrosilicon was confirmed by the SEM and EDS analysis shown in Fig. 7, where only Fe and Si peak was detected with low intensity carbon peak. Brighter phase in SEM image represents the higher iron concentration and darker phase represents the higher silicon concentration.

Figure 8 is showing $f=k t$ and $-\ln (1-X)=k t$ plot of graphite and Bakelite pellet over time to determine the possible controlling mechanism in each stage of the reduction process. In stage 1, though graphite and Bakelite pellet showed linearity differently, in both case, $X$ and $-\ln (1-X)$, the slopes are nearly linear which implies that the rate is not controlled by one single mechanism, but a mixed control of possibly, mass transfer and chemical kinetics. ${ }^{21)}$ However in Stage 2 I and II, the curve shows better linearity when plotted with $-\ln (1-X)$, which indicate that the reaction mechanism is predominantly controlled chemically. ${ }^{21)}$ This is also in agreement with the XRD results (Fig. 6), where it was observed that formation of $\mathrm{Fe}_{5} \mathrm{Si}_{3}, \mathrm{FeSi}, \mathrm{SiC}, \mathrm{CaSiO}_{3}$ phase occurred within this stage (120 to 900 seconds) through chemical reactions.

It is first necessary to find the reaction at equilibrium to determine which reactions are controlling in the system. ${ }^{22)}$ A given reaction is at equilibrium when the off-gas $\mathrm{P}_{\mathrm{CO}} /$ $\mathrm{P}_{\mathrm{CO} 2}$ concentration falls on the equilibrium $\mathrm{P}_{\mathrm{CO}} / \mathrm{P}_{\mathrm{CO} 2}$ value for that reaction. ${ }^{22)}$ From literature it is evident that indirect reduction by $\mathrm{CO}$ is dominant in iron oxide reduction (reaction (5)) instead of direct reduction by carbon. ${ }^{13,23)}$ The two major intermediate products, $\mathrm{SiC}$ and $\mathrm{SiO}$ formation is also known to occur through gas phase reduction by $\mathrm{CO}$ in silica reduction (reactions (3), (7)). ${ }^{24)}$ And Boudouard reaction (reaction (6)) exists at temperature above $1273 \mathrm{~K}$ $\left(1000^{\circ} \mathrm{C}\right)$ and plays a vital role both iron oxide and silica reduction studies. ${ }^{24,25)}$ Therefore these reactions are considered to plot $\ln \left(\mathrm{P}_{\mathrm{CO}} / \mathrm{P}_{\mathrm{CO} 2}\right)$ plot though ferrosilicon production involves a number chemical reactions including silica reduction and iron oxide reduction.

$$
\begin{array}{r}
\mathrm{Fe}_{2} \mathrm{O}_{3}(\mathrm{~s})+3 \mathrm{CO}(\mathrm{g}) \rightarrow 2 \mathrm{Fe}(\mathrm{s} / \mathrm{l})+3 \mathrm{CO}_{2}(\mathrm{~g}) \ldots . \text { reaction (5) } \\
\mathrm{C}(\mathrm{s})+\mathrm{CO}_{2}(\mathrm{~g}) \rightarrow 2 \mathrm{CO}(\mathrm{g}) \ldots . . . \text { reaction (6) } \\
\mathrm{SiO}_{2}(\mathrm{~s})+\mathrm{CO}(\mathrm{g}) \rightarrow \mathrm{SiO}(\mathrm{g})+\mathrm{CO}_{2}(\mathrm{~g}) \ldots \ldots . . . \text { reaction (3) } \\
\mathrm{SiO}_{2}(\mathrm{~s})+4 \mathrm{CO}(\mathrm{g}) \rightarrow \mathrm{SiC}(\mathrm{s})+3 \mathrm{CO}_{2}(\mathrm{~g}) \ldots \ldots . . \text { reaction }(7)
\end{array}
$$

Figure 9 is showing the oxygen potential of the reaction off-gas which was calculated in terms of $\mathrm{P}_{\mathrm{CO}} / \mathrm{P}_{\mathrm{CO} 2}$ and compared with equilibrium $\mathrm{P}_{\mathrm{CO}} / \mathrm{P}_{\mathrm{CO} 2}$ of the individual reactions. From the graph it can be observed that stage 1, is mostly controlled by iron oxide reduction $\left(\mathrm{Fe}_{2} \mathrm{O}_{3} \rightarrow \mathrm{Fe}_{3} \mathrm{O}_{4} \rightarrow \mathrm{FeO} \rightarrow\right.$ $\mathrm{Fe}$ ), while stage 2-I is controlled by $\mathrm{SiO}$ formation and Boudouard reaction for both graphite and Bakelite bearing pellet. In stage 2-II and stage $3, \ln \left(\mathrm{P}_{\mathrm{CO}} / \mathrm{P}_{\mathrm{CO} 2}\right)$ concentration of Bakelite pellet shows that Boudouard reaction is at equilibrium, therefore $\mathrm{SiO}$ and $\mathrm{SiC}$ formation through 
(a) Stage 1 ( 0 - 120 seconds)
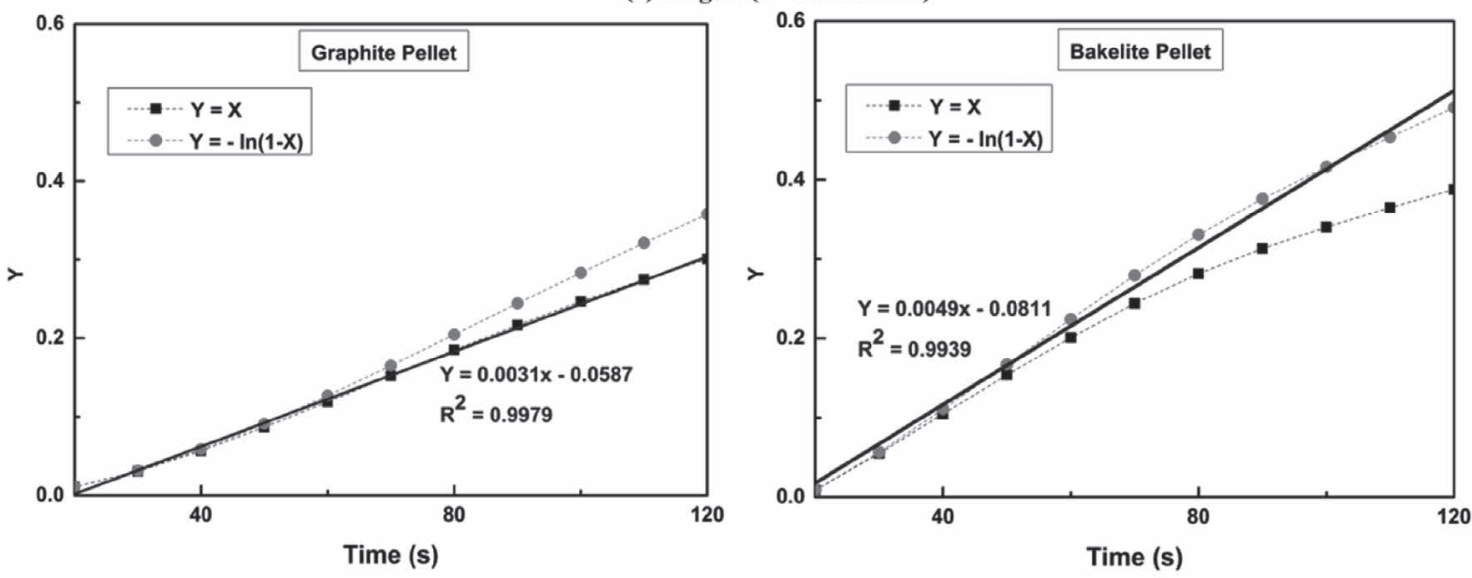

(b) Stage 2-I (120 - 400 seconds)
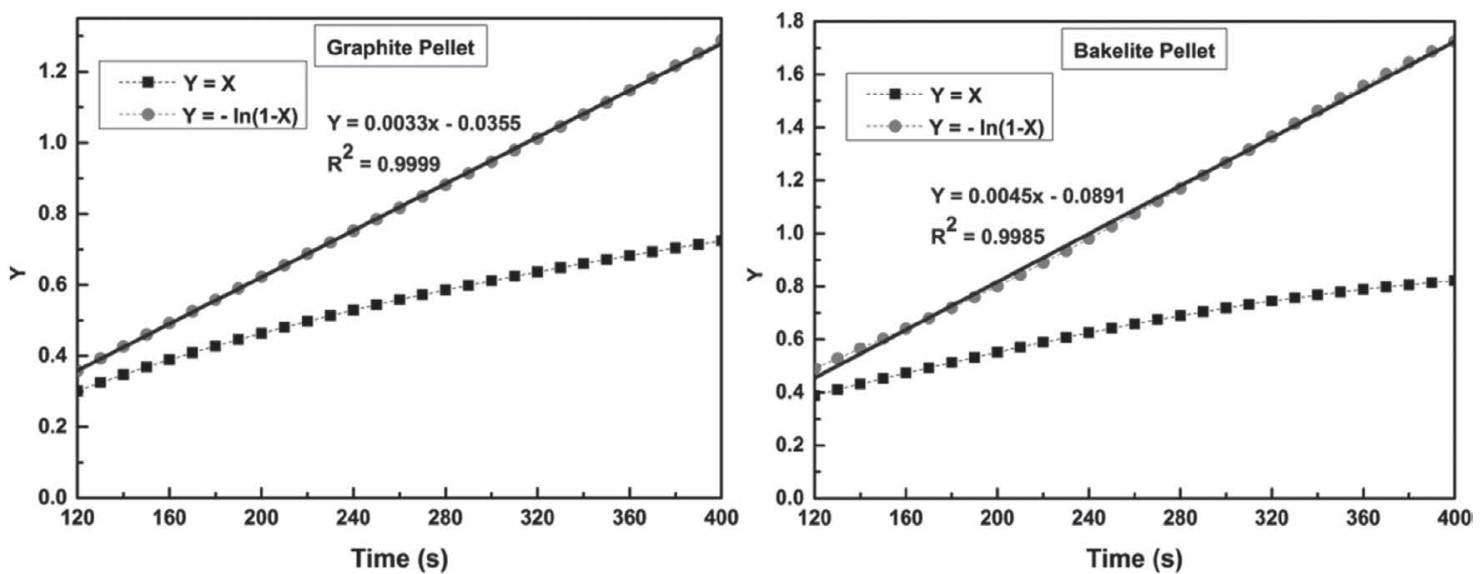

(c) Stage 2-II (400 - 900 seconds)
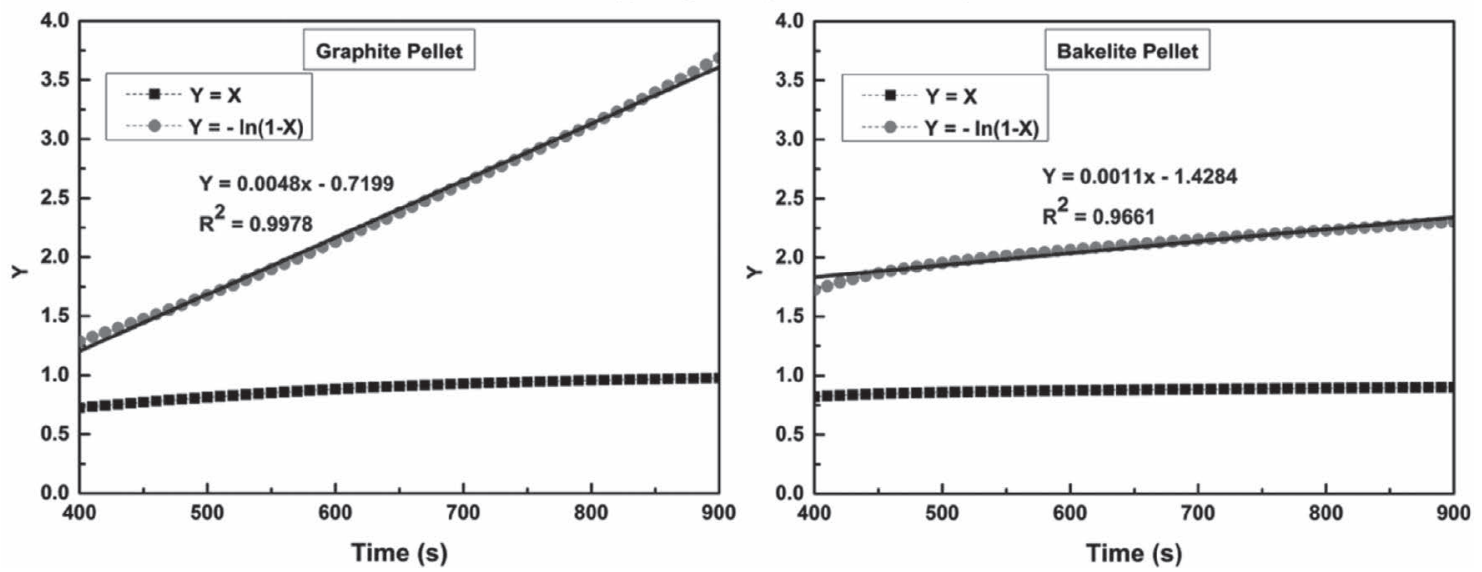

Fig. 8. Reduction of graphite and Bakelite pellet at $1823 \mathrm{~K}\left(1550^{\circ} \mathrm{C}\right)$ during synthesis of ferrosilicon to determine various controlling mechanisms.

the gas phase reduction reactions of silica are the rate controlling reactions. Instead, in graphite pellet at stage 2-II, $\ln \left(\mathrm{P}_{\mathrm{CO}} / \mathrm{P}_{\mathrm{CO} 2}\right)$ value located between mixed Boudouard and $\mathrm{SiO}$ formation reaction control. Therefore in graphite bearing pellet, Boudouard reaction is also attributed to the controlling reactions along with $\mathrm{SiO}$ formation in stage 2-II. At stage 3 , graphite pellet showing equilibrium towards Boudouard reaction showing less control in the system. At stage $3(\sim 900 \mathrm{sec})$, reaction already completed and due to the formation of the reaction product like ferrosilicon and deposition of slag $\left(\mathrm{SiC} / \mathrm{CaSiO}_{3}\right)$ by reduction, reaction was retarded. Therefore, reduction extent also showed steady state (Fig. 5). In-situ images of pellets at different stages are shown in Fig. 10. In stage 2 we could visually distinguish the formation of ferrosilicon alloys through the reduction reaction which is in agreement with the previous discussion. In-situ images at stage 3 also showed that the reduction became stable and synthesized metal droplets of ferrosilicon alloy was distinguishable from slag.

Temperature is an important factor that influences the rate of reactions. The dependency of reaction rate on temperature can be described by the activation energy, $E_{a}$ defined 
by Arrhenius equation. The activation energy represents the energy level that the reactant molecules must overcome to start the reaction to occur.

$$
k=k_{0} \mathrm{e}^{-\mathrm{Ea} / \mathrm{RT}}
$$

Here, $k$ is the rate constant derived from the plot of $-\ln (1-X)$ as function of time in stage 1 and 2 at temperature $1623 \mathrm{~K}, 1723 \mathrm{~K}$ and $1823 \mathrm{~K}\left(1350^{\circ} \mathrm{C}, 1450^{\circ} \mathrm{C}\right.$ and $1550^{\circ} \mathrm{C}$ ). A plot of $\ln (k)$ over $1 / T$, is shown in Fig. 11, indicates the good linearity and yields an activation energy of $169.76 \mathrm{~kJ} / \mathrm{mol}$ and $55.91 \mathrm{~kJ} / \mathrm{mol}$ for graphite and Bakelite pellet for stage 1. For Stage 2, activation energy for graphite and Bakelite pellet is $238.07 \mathrm{~kJ} / \mathrm{mol}$ and $140.29 \mathrm{~kJ} / \mathrm{mol}$ respectively. It is noted that, activation energy for stage 1 and 2 for Bakelite pellet is lower than the graphite pellet. Initial gas generation from Bakelite, comparatively less crystalline nature of Bakelite derived carbon and less dependence on Boudouard reaction can be attributed to the lower activation energy. Moreover, both in graphite and Bakelite pellet activation energy is higher in stage 2 compared to stage 1 . During stage 1, mostly iron oxide reduction was dominant and lower activation energy for iron oxide reduction can be attributed to the lower $\mathrm{E}_{\mathrm{a}}$ value during stage 1 . Reported activation energies of silica reduction are in the

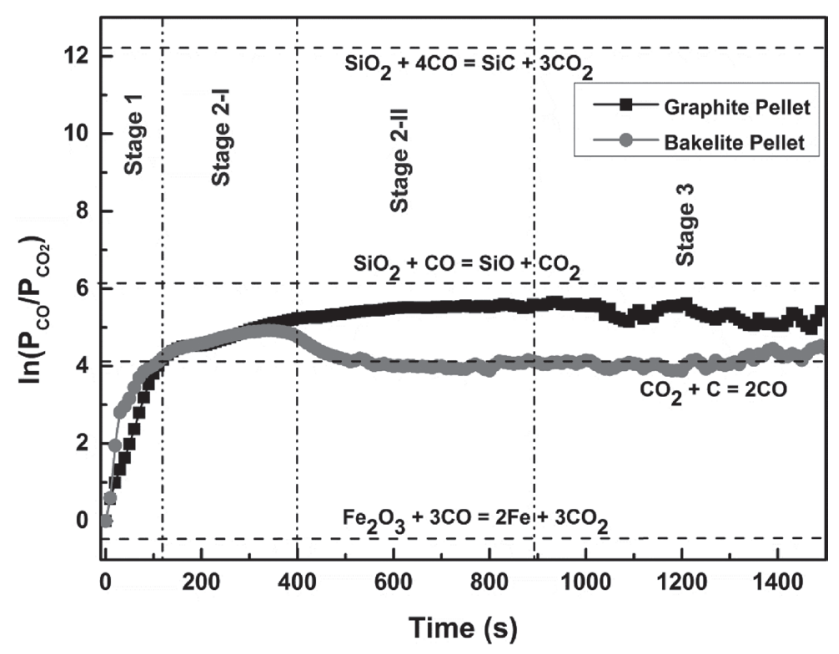

Fig. 9. Measured and equilibrium $\ln \left(\mathrm{P}_{\mathrm{CO}} / \mathrm{P}_{\mathrm{CO} 2}\right)$ values for the graphite and Bakelite pellet at $1823 \mathrm{~K}\left(1550^{\circ} \mathrm{C}\right)$ during synthesis of ferrosilicon. range of $230 \mathrm{~kJ} / \mathrm{mol}$ to $552 \mathrm{~kJ} / \mathrm{mol}$, depending primarily on the precursor silica and carbon sources, particle sizes, temperature ranges and the broad range of rate equation form which have been fit to the data. ${ }^{2,27)}$ Also Filsinger and Bourrie ${ }^{9)}$ reported activation energy within range of 305 $\mathrm{kJ} / \mathrm{mol}$ to $505 \mathrm{~kJ} / \mathrm{mol}$ within $1683 \mathrm{~K}$ to $2073 \mathrm{~K}\left(1410^{\circ} \mathrm{C}\right.$ to $1800^{\circ} \mathrm{C}$ ) temperature for specific silica reduction reaction which covers $\mathrm{SiC}, \mathrm{SiO}$ and $\mathrm{Si}$ formation. The activation energies reported in this work are comparatively lower than the previously reported silica reduction studies. This study
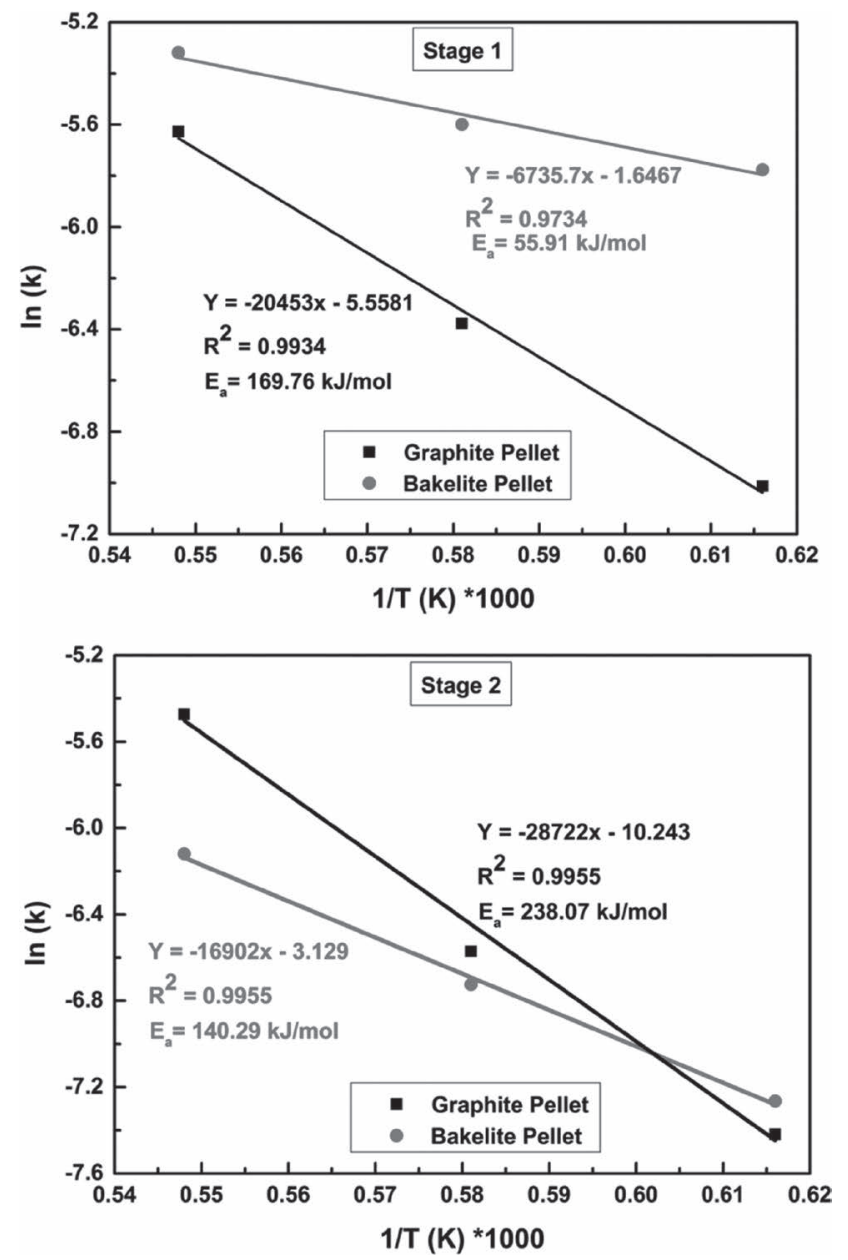

Fig. 11. determination of activation energy of the graphite and Bakelite pellet at $1823 \mathrm{~K}\left(1550^{\circ} \mathrm{C}\right)$ during synthesis of ferrosilicon.
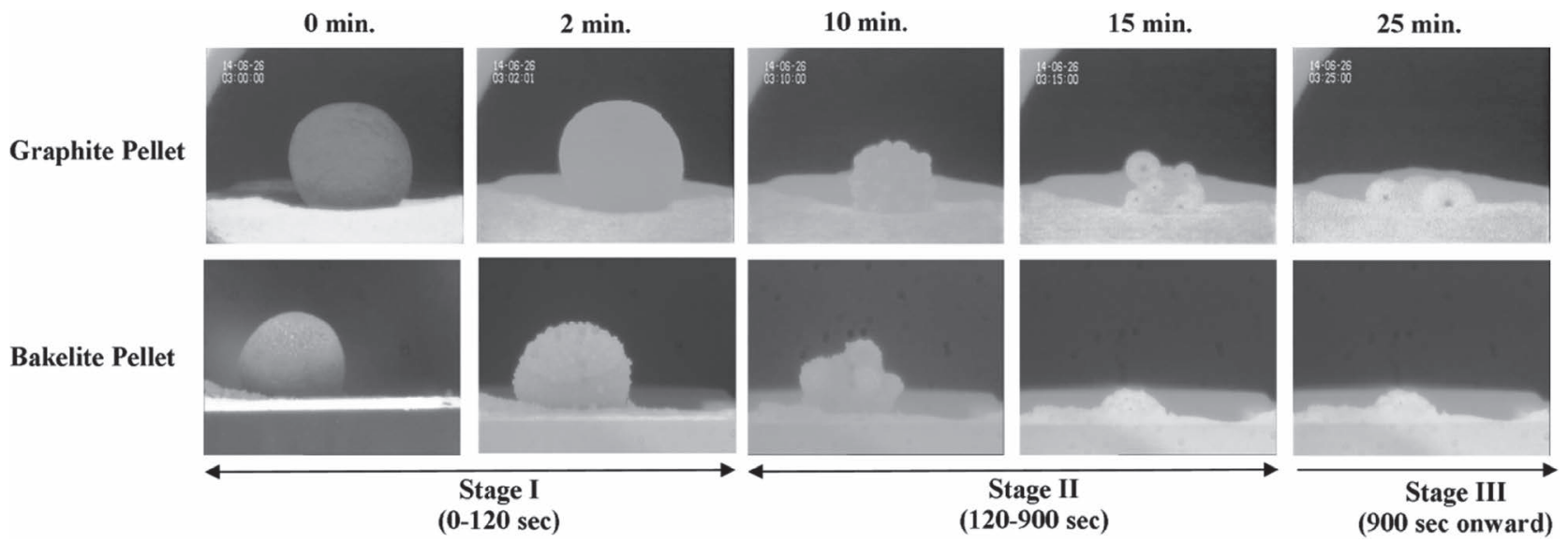

Fig. 10. In-situ images of graphite and Bakelite pellet at $1823 \mathrm{~K}\left(1550^{\circ} \mathrm{C}\right)$ during synthesis of ferrosilicon. 
is not purely silica reduction as iron oxide was also used to produce ferrosilicon and reduction of iron oxide and solute iron could play the vital role to reduce the value of activation energy in the reaction mechanism.

As indicated in Fig. 11, the reaction with higher activation energy, $E_{a}$ has a steeper slope; which represents that the reaction rate of graphite pellet is very sensitive to temperature change. This behavior is also in agreement with cumulative oxygen removal pattern (Fig. 4). In contrast, the reaction with a lower $E_{a}$ is less sensitive to a temperature change. Therefore Bakelite pellet can be useful as a reductant even at moderately lower temperature to synthesise ferrosilicon alloy.

\section{Conclusions}

A fundamental comparative study on reaction kinetics and mechanism of ferrosilicon alloy synthesis, using reagent grade material, graphite and waste plastic, Bakelite as reducing agent is established. Off-gases evolving from reduction reactions were considered to determine the reaction rate and controlling mechanism. Based on present experiments, major conclusions are summarized as follows:

(1) Extent of reduction to synthesise ferrosilicon alloy by using either graphite or Bakelite as reductant, can be improved by increasing temperature. Though, Bakelite pellet showed lower dependency on temperature compared to graphite. Activation energy for graphite and Bakelite bearing pellet is $238.07 \mathrm{~kJ} / \mathrm{mol}$ and $140.29 \mathrm{~kJ} / \mathrm{mol}$ respectively.

(2) Stages (1 to 3 ) in pellet reactions were determined on change in slope in reduction extent over time curve and in $\ln \left(\mathrm{P}_{\mathrm{co}} / \mathrm{P}_{\mathrm{co} 2}\right)$ over time curve. Stage 1 and $2 \mathrm{I}$, was mostly controlled by iron oxide reduction followed by $\mathrm{SiO}$ formation and Boudouard reaction for both graphite and Bakelite bearing pellet. In stage 2-II, Bakelite pellet showed that Boudouard reaction reached at equilibrium, therefore $\mathrm{SiO}$ and $\mathrm{SiC}$ formation through the gas phase reduction reactions of silica are the rate controlling reactions. Instead, in graphite pellet at stage 2-II, showed mixed control of Boudouard and $\mathrm{SiO}$ formation reactions. At stage 3, reaction already completed and due to the formation of the reaction product like ferrosilicon and deposition of slag $\left(\mathrm{SiC} / \mathrm{CaSiO}_{3}\right)$ by reduction, reaction was retarded for both graphite and Bakelite bearing pellet.

(3) The overall reduction mechanism was predominantly controlled by chemical reactions with both the reducing agent. Initially Bakelite bearing pellet showed faster reaction rate compared to graphite due to volatiles genera- tion and less crystalline nature of Bakelite derived carbon.

(4) This comparative study will create new opportunities to use waste Bakelite as a reducing agent at lower temperature compared to conventional carbon materials to synthesise ferrosilicon alloy.

\section{Acknowledgments}

The authors would like to acknowledge the financial support received from the Australian Research Council (ARC) and OneSteel for this project (LP120100337).

\section{REFERENCES}

1) A. Schei, J. K. Tuset and H. Tveit: Production of High Silicon Alloys, Tapir, Trondheim, Norway, (1998).

2) S. Ramakrishnan and P. Koltun: Resour. Conserv. Recycl., 42 (2004), 49.

3) T. Videm: Proc. 7th Int. Ferro-Alloys Cong. (INFACON), Norweigian Ferroalloy Research Organization (FFF), Trondheim, (1995), 221.

4) V. Myrvagnes and T. Lindstad: Proc. 11th Int. Ferro-Alloys Congress (INFACON 11), Vol.18, Indian Ferro Alloy Producers' Association, Mumbai, (2007), 402.

5) T. V. Buø, R. J. Gray and R. M. Patalsky: Int. J. Coal Geol., 43 (2000), 243.

6) J. Biernacki and G. Wotzak: J. Am. Ceram. Soc., 72 (1989), 122.

7) S. Hutchison, L. Richardson and C. M. Wai: Metall. Trans. B, 19 (1988), 249.

8) M. Nagamori, I. Malinsky and A. Claveau: Metall. Trans. B, 17 (1986), 503.

9) D. H. Filsinger and D. B. Bourrie: J. Am. Ceram. Soc., 73 (1990), 1726.

10) E. Myrhaug, J. Tuset and H. Tveit: Proc. 10th Int. Ferroalloys Cong., South African Institule of Mining and Metallugy, Johannesburg, (2004), 4.

11) L. Baekeland: Ind. Eng. Chem., 1 (1909), 149.

12) R. Thomas, P. Vijayan and S. Thomas: Recent Developments in Polymer Recycling, Transworld Research Network, Kerala, (2011), 121.

13) H. Park and V. Sahajwalla: Metall. Mater. Trans. B, 44 (2013), 1379.

14) R. Farzana and V. Sahajwalla: J. Sustain. Metall., 1 (2015), 65.

15) R. Farzana, R. Rajarao and V. Sahajwalla: Ind. Eng. Chem. Res., 53 (2014), 19870.

16) R. Farzana, R. Rajarao and V. Sahajwalla: Iron \& Steel Technology Conf. and Exposition (AISTech 2014), AIST, Warrendale, PA, (2014), CD-ROM.

17) R. Farzana and V. Sahajwalla: Proc. 8th Pacific Rim Int. Cong. on Advanced Materials and Processing (PRICM), John Wiley \& Sons, Hawaii, (2013), 2267.

18) R. Farzana, R. Rajarao and V. Sahajwalla: Mater. Lett., 116 (2014), 101.

19) B. Monsen, L. Kolbeinsen, S. Prytz, V. Myrvágnes and K. Tang: Proc. 13th Int. Ferroalloys Cong., P. Dipner, Almaty, (2013), 467.

20) H. Sun, K. Mori and R. Pehlke: Metall. Trans. B, 24 (1993), 113.

21) I. Sohn and R. Fruehan: Metall. Mater. Trans. B, 36 (2005), 605.

22) J. Moon and V. Sahajwalla: ISIJ Int., 43 (2003), 1136.

23) R. Fruehan: Metall. Trans. B, 8 (1977), 279.

24) M. Gasik: Handbook of Ferroalloys: Theory and Technology, Butterworth-Heinemann, Oxford, (2013).

25) J. Moon and V. Sahajwalla: Metall. Mater. Trans. B, 37 (2006), 215.

26) A. W. Weimer, K. J. Nilsen, G. A. Cochran and R. P. Roach: AIChE J., 39 (1993), 493.

27) H. Sun, K. Mori and R. D. Pehlke: Metall. Trans. B, 24 (1993), 113. 